\title{
Type: Original Research
}

\section{Title:}

\section{Determination of clinical risk factors associated with inflammation in hypertensive patients with type-2 diabetes mellitus}

Subtitle: Risk factors in hypertensive patients with type-2 diabetes mellitus

\section{Author}

Mohammed S. Ellulu1, ${ }^{1 *}$ (Orcid ID: http://orcid.org/0000-0003-1671-799X)

\section{Author's Identifying Information}

${ }^{1}$ Department of Clinical Nutrition, Faculty of Applied Medical Sciences, Al-Azhar University of Gaza, Palestine

${ }^{2}$ Clinical Nutrition Specialist, Gaza, Palestine

* Corresponding author: Mohammed S. Ellulu, Department of Clinical Nutrition, Faculty of Applied Medical Sciences, Al-Azhar University of Gaza, Palestine. Address: Gaza, Palestine. Tel: +970-59-9784862, E-mail: mohdsubhilulu@gmail.com. 


\title{
Determination of clinical risk factors associated with inflammation in hypertensive patients with type-2 diabetes mellitus
}

\begin{abstract}
Background: Obesity and chronic diseases associated with the development of inflammation have remained unclear if the observed inflammatory state in diabetic patients is due to excess adipose tissue mass and/or directly associated with the diabetic state. Therefore, this study determined the risk factors associated with inflammation in hypertensive patients with type-2 diabetes mellitus.
\end{abstract}

Methods: A total of 164 hypertensive diabetic patients aged 38 to 60 years were selected from seven primary health care centers in Gaza city, Palestine. Interview and questionnaire were employed to collect data related to age, gender, smoking habits, and physical activity pattern. Besides, the selection of patients depended on objective criteria.

Results: The study involved $118(72 \%)$ women and $46(28 \%)$ men. The mean of age for all patients was $53.7 \pm 0.46$ years old. 76 patients $(46.3 \%)$ were categorized as current smokers, 88 patients (53.7\%) categorized as non-smokers. The baseline distribution of patients according to physical activity has displayed that $130(79.3 \%)$ were low physically active patients, $28(27.1 \%)$ were moderate, and $6(3.7 \%)$ were highly physically active patients. A tertile of inflammation feature with high sensitivity C-reactive protein (hs-CRP) was developed. The highest tertile of hs-CRP was significantly associated with women, higher obesity indices, metabolic dysregulation involving lipid profile markers, fasting blood glucose (FBG) and blood pressure, higher interleukin 6 (IL-6), and lower adiponectin. Via ordinal logistic regression analysis, after adjusting for age, gender, smoking habits, and physical activity; the risk factors for hs-CRP were the increased body mass index [OR: 1.17, $\mathrm{P}=0.018$ ], IL-6 [OR: 2.22, $\mathrm{P}=0.025]$ and FBG [OR: 1.01, $\mathrm{P}=0.007]$, as well as reduced adiponectin [OR: $0.81, \mathrm{P}=0.002]$.

Conclusion: The inflammation state was affected by obesity and had been related to altered adipokines levels of IL-6 and adiponectin, as well as affected by the disease condition of diabetes, as evidenced by higher serum level of FBG.

Keywords: Obesity, inflammation, diabetes, hypertension, adipokines, adiponectin, interleukin 6, C-reactive protein, blood glucose.

\section{INTRODUCTION}

The World Health Organization (WHO) rates hypertension (HT) as one of the most important causes of premature death worldwide [1]. It is one of the most important preventable causes of death worldwide and one of the commonest conditions treated in primary care in the United Kingdom, where it affects more than a quarter of all adults and over half of those over the age of 65 [2]. In addition, HT was ranked as the third most important risk factor for attributable burden of disease in south Asia in 2010 [3]. In fact, the uncontrolled HT has been associated with developed nephropathy, retinopathy, ischemic heart disease, peripheral vascular disease [4], and inflammation [5,6]. According to the German Institute of Human Nutrition (DIFE), the uncontrolled HT has been associated with the development of type-2 diabetes mellitus (T2DM) [7]. 
Diabetes mellitus is a group of diseases marked by high level of blood glucose [8]. According to the American Diabetes Association, the T2DM is a result of insulin resistance that leads to a progressive defect of insulin secretion [9]. T2DM leads to progressive complications like neuropathy, retinopathy, kidney disease, and heart disease [10]. It also worsens arterial stiffness in hypertensive patients through endothelial dysfunction [11], and increases the incidence of metabolic dysregulation, oxidative stress, and inflammation $[12,13]$. From these associated complications; patients suffer greatly, and result in an increased number of years lived with disability [14].

On the other hand, obesity, the accumulation of abnormal or excessive fat [15], is the fifth leading risk for global deaths [16]. It has been classified as one of the primary causes of elevated blood pressure (BP) among adults [17], and increases the risk of developing HT irrespective of race or gender [18]. Furthermore, obesity, and especially visceral adipose tissue accumulation, increases the risk of impaired insulin tolerance [19] and the development of T2DM [20]. The greater risk of T2DM among the obese can partly be explained by the changes in adipose tissue function [21]. Besides, epidemiological studies have demonstrated inflammation evidenced by the elevated plasma levels of inflammatory markers, including C-reactive protein (CRP), interleukin 6 (IL-6), and tumor necrosis factor alpha (TNF- $\alpha$ ), in patients with metabolic syndrome and T2DM [22,23]. Moreover, the studies have indicated lower plasma level of adiponectin, which is totally antiinflammatory markers and insulin-sensitizing factors, in obese individuals [24], cardiovascular patients, metabolic syndrome, and T2DM [25].

As reported, the conditions of obesity, HT, and T2DM are well associated with inflammation [26,27]. Thence, inflammation due to increased plasma level of CRP can lead, over the time, to metabolic syndrome [28], atherosclerosis and coagulation [29], cardio-metabolic risks [30], and heart attack [31]. However, it remains unclear if the observed alterations in plasma cytokines and/or inflammatory markers in T2DM are due to excess adipose tissue mass and/or directly associated with the diabetic state [32]. Therefore, this study identified the clinical risk factors associated with inflammation evidenced by high sensitivity C-reactive protein (hs-CRP) in hypertensive diabetic patients.

\section{RESEARCH DESIGN AND METHODS}

\section{Study subjects}

In this study, a total of 164 hypertensive patients with type-2 diabetes mellitus "hypertensive diabetic" out of 484 subjects screened; those non-insulin dependent and aged 38-60 years old were selected from seven primary health care centers that were controlled by the Ministry of Health in Gaza city, Palestine via cluster random sampling, from November 2013 to May 2014. The study was ethically approved by the Helsinki Committee for Ethical Approval of Gaza (Number: PHRC/HC/11/13). All patients had a stable weight with no fluctuation of $>2 \%$ of their body weight for at least two months prior to this study. Other than that, patients who suffered conditions that might affect the laboratory results like acute or chronic inflammatory diseases, including infections, arthritis, cancers, heart disease, liver and renal diseases, or regularly used medicines like insulin, NSAIDs such as COX-2 inhibitors, and antibiotics, were excluded. Furthermore, physiological changes like pregnancy and breast feeding states were also excluded.

Personal information collected via interview and questionnaire involved age, gender, health/disease history, and medicine usage. Besides, the lifestyle factors involved smoking habits and physical activity pattern. The smoking habits were assessed based on modified form of The Behavioral Risk Factor Surveillance System 
that had been approved by the Centers for Disease Control and Prevention (CDC) Survey Data [33]. The patients were categorized into two groups; the first group comprised of current smokers that involved both active and passive smokers, while the second group consisted of non-smokers that involved past smokers and never smokers. Meanwhile, physical activity pattern was evaluated based on the Global Physical Activity Questionnaire (GPAQ) Version-2 that had considered the Palestinian specialties [34]. The patients were grouped into one out of the three categories based on the intensity of physical activity that had been classified as low, moderate, and high.

\section{Tools}

A Seca Stadiometer was used to assess body mass index (BMI) based on the World Health Organization, calculated by using height and weight based on the formula [BMI $\left(\mathrm{kg} / \mathrm{m}^{2}\right)=$ Weight $(\mathrm{kg}) /$ Height square $\left(\mathrm{m}^{2}\right)$ ] [35], and a Seca 201 non-elastic tape was used to determine WC based on the National Institute for Health and Clinical Excellence classification [36] (men: normal $<102 \mathrm{~cm}$, high $\geq 102 \mathrm{~cm}$; women: normal $<88 \mathrm{~cm}$, high $\geq 88 \mathrm{~cm})$.

Besides, quantitative method was employed to assess fasting blood glucose (FBG), total cholesterol (TC), triglyceride (TG), and high sensitivity C-reactive protein (hs-CRP). A CRP turbidimetric latex 1:5 kit was used to assess hs-CRP, while an enzymatic colorimetric method with glucose oxidase was used to estimate FBG, and commercial kits were used to assess TC and TG. All quantitative data were evaluated by using a Mindray BS-120 Chemistry Analyzer. Meanwhile, interleukin 6 (IL-6) and adiponectin were assessed by using enzyme-linked immunosorbent assay (ELISA) kits (Sigma-Aldrich Co) via One-Run reading. Besides, blood samples were collected by trained nurses or physicians at the health centers. The $7 \mathrm{~mL}$ blood sample was drawn into a polyethylene evacuated tube, and then, divided into two separate tubes. One of the tubes that contained blood sample was used to evaluate quantitative biochemical measures (hs-CRP, FBG, TC, and $\mathrm{TG}$ ), while the other was stored at $-80^{\circ} \mathrm{C}$, after separation from serum, for analysis through one-run of an ELISA reader to assess IL-6 and adiponectin.

In addition, $\mathrm{BP}$ was determined through validation and standard mercury sphygmomanometer, where systolic BP (SBP) was defined as the appearance of first sound (Korotkoff phase 1), and diastolic BP (DBP) was the disappearance of the sound (Korotkoff phase 5) during deflation of the cuff at a 2-3 $\mathrm{mmHg} / \mathrm{second}$ reduction rate of the mercury column. Two successive BP readings were obtained at 5 minutes intervals and averaged.

\section{Statistical analysis}

The data obtained were analyzed by using the Statistical Package for Social Sciences version 21.0 software (SPSS Inc., Chicago, IL, USA). Descriptive statistics, including Chi-square $\left(\chi^{2}\right)$, was used to compare the categorical variables. The central tendency of continuous variables was presented by mean \pm standard error of mean (SEM). Then, a tertile of hs-CRP was created; where One-Way ANOVA was used to detect the differences between the tertile groups, whereas the Ordinal Logistic Regression was used to estimate the $\operatorname{Exp}(B)$ [Odds Ratio (OR)] after adjustments were made for age, gender, smoking habits, and physical activity. Meanwhile, the Bivariate analysis via Pearson's correlation coefficient explained the relationships of hs-CRP with BMI, IL-6, adiponectin, and FBG. The $p$ value of $\leq 0.05$ was considered as statistically significant and the level of confidence was $95 \%$.

\section{RESULTS}


A total of 164 HT patients with T2DM were recruited in this study to identify the clinical risk factors associated with inflammation evidenced by hs-CRP. The study involved 118 (72\%) women and 46 (28\%) men. The mean of age for all patients was $53.7 \pm 0.46$ years old. Lifestyle habits included smoking and physical activity patterns. 76 patients $(46.3 \%)$ who were categorized as current smokers had been active and passive smokers, while 88 patients $(53.7 \%)$ categorized as non-smokers were past smokers and never smokers. Finally, the baseline distribution of patients, according to physical activity, displayed high percentage of low physical activity for 130 patients $(79.3 \%), 28(27.1 \%)$ were moderate, and $6(3.7 \%)$ were highly physically active patients.

As shown in Table 1, the recruited patients were distributed into one of three groups based on hs-CRP tertile. The tertile of hs-CRP $(\mathrm{mg} / \mathrm{L})$ was categorized as in the following: Low, hs-CRP $<3.71 \mathrm{mg} / \mathrm{L}(\mathrm{n}=55)$; Moderate, hs-CRP=3.71-8.99 mg/L ( $\mathrm{n}=54)$; and High, hs-CRP $>8.99 \mathrm{mg} / \mathrm{L}(\mathrm{n}=55)$. The distribution of gender to hs-CRP tertile revealed significant difference, as the percentages of women increased high-moderate-low tertile movement, while the percentages of men moved inversely; they decreased in high-moderate-low tertile movement. However, no difference was obtained for age due to the changed hs-CRP tertile, as well as the changes of smoking habits and physical activity that exhibited non-significant distribution.

In addition, the increased measures of obesity markers BMI and WC have been associated significantly with high hs-CRP tertile $(\mathrm{P}<0.01)$. BMI of low tertile $\left(27.69 \pm 0.95 \mathrm{~kg} / \mathrm{m}^{2}\right)$ and moderate tertile $\left(34.86 \pm 1.28 \mathrm{~kg} / \mathrm{m}^{2}\right)$ showed lower significance compared to high tertile $\left(37.86 \pm 0.81 \mathrm{~kg} / \mathrm{m}^{2}\right) ; \mathrm{P}<0.001$ and $\mathrm{P}=0.011$, respectively. Moreover, WC of low tertile had lower significance than high tertile $(112.62 \pm 1.67 \mathrm{vs} .119 .95 \pm 1.49 \mathrm{~cm}$, $\mathrm{P}<0.009)$. Nevertheless, no difference was discovered for SBP, while DBP for high tertile had been higher than that with low significance $(88.73 \pm 1.58$ vs. $80.42 \pm 2.38 \mathrm{mmHg}, \mathrm{P}=0.026)$.

On the other hand, regarding metabolic markers, FBG, TC, and TG showed significant changes with differences in hs-CRP tertile. The lower tertile of hs-CRP had lower significance than higher category for FBG (146.90 \pm 12.92 vs. $207.33 \pm 9.64 \mathrm{mg} / \mathrm{dL}, \mathrm{P}<0.001)$. As for TC, the lower tertile of hs-CRP $(194.10 \pm 4.95$ $\mathrm{mg} / \mathrm{dL})$ had lower significance than moderate $(208.03 \pm 7.28 \mathrm{mg} / \mathrm{dL})$ and high tertile $(209.69 \pm 5.37 \mathrm{mg} / \mathrm{dL})$; $\mathrm{P}=0.012$ and $\mathrm{P}=0.008$, respectively. Meanwhile, for $\mathrm{TG}$, the lower tertile of hs-CRP $(166.76 \pm 18.08 \mathrm{mg} / \mathrm{dL})$ had lower significance than moderate $(234.10 \pm 24.00 \mathrm{mg} / \mathrm{dL})$ and high tertile $(235.69 \pm 13.76 \mathrm{mg} / \mathrm{dL})$; $\mathrm{P}=0.006$ and $\mathrm{P}<0.001$, respectively.

On the relation of adipokines, IL-6 and adiponectin showed significant changes with differences in hs-CRP tertile. For IL-6, the lower tertile of hs-CRP $(1.60 \pm 0.10 \mathrm{pg} / \mathrm{mL})$ had lower significance than moderate $(2.05 \pm 0.12 \mathrm{pg} / \mathrm{mL})$ and high tertile $(2.39 \pm 0.11 \mathrm{pg} / \mathrm{mL}) ; \mathrm{P}=0.005$ and $\mathrm{P}<0.001$, respectively. Inversely for adiponectin, the higher tertile of hs-CRP $(8.55 \pm 0.53 \mathrm{mg} / \mathrm{L})$ had lower significance than moderate $(10.93 \pm 0.62 \mathrm{mg} / \mathrm{L})$ and low tertile $(13.20 \pm 0.98 \mathrm{mg} / \mathrm{L}) ; \mathrm{P}=0.025$ and $\mathrm{P}<0.001$, respectively.

Therefore, in order to identify the risk factors associated with increasing a tertile of serum hs-CRP; Ordinal Logistic Regression was used after adjustments were made for age, gender, smoking habits, and physical activity (Test of Parallel Lines: $\mathrm{P}=0.968$ ). However, the factors of WC, SBP, DBP, TC, and TG did not reach the significance level as risk factors. Nonetheless, the risk factors that had been associated with increased hsCRP tertile were increased BMI [OR: 1.17, $\mathrm{P}=0.018$ ], increased FBG [OR: 1.01, $\mathrm{P}=0.007$ ], increased IL-6 [OR: 2.22, $\mathrm{P}=0.025$ ], and reduced Adiponectin [OR: 0.81, $\mathrm{P}=0.002$ ].

[Table 1: Distribution of participants' characteristics according to serum hs-CRP tertile] 
bioRxiv preprint doi: https://doi.org/10.1101/613711; this version posted April 18, 2019. The copyright holder for this preprint (which was not certified by peer review) is the author/funder, who has granted bioRxiv a license to display the preprint in perpetuity. It is made available under aCC-BY 4.0 International license.

\begin{tabular}{|c|c|c|c|c|c|c|}
\hline & \multicolumn{3}{|c|}{ Tertile of plasma hs-CRP (mg/L) } & \multirow{2}{*}{$\begin{array}{l}\text { Estimate } \\
95 \% \mathrm{CI}\end{array}$} & \multirow{2}{*}{$\begin{array}{c}\mathrm{OR} / \\
\operatorname{Exp}(\mathrm{B})\end{array}$} & \multirow{2}{*}{$\begin{array}{c}\mathrm{P} \\
\text { value }\end{array}$} \\
\hline & $\begin{array}{c}\text { Low } \\
(<3.71)\end{array}$ & $\begin{array}{c}\text { Moderate } \\
(3.71-8.99) \\
\end{array}$ & $\begin{array}{c}\text { High } \\
(>8.99)\end{array}$ & & & \\
\hline Number & 55 & 54 & 55 & & & \\
\hline hs-CRP (mg/L)** & $2.16 \pm 0.13$ & $6.27 \pm 0.22$ & $17.77 \pm 1.88$ & & & \\
\hline Age (years) & $53.85 \pm 0.79$ & $53.74 \pm 0.86$ & $53.49 \pm 0.76$ & & & 0.281 \\
\hline \multicolumn{7}{|l|}{ Gender** } \\
\hline$\%$ Women & 26.3 & 34.7 & 39.0 & & & 0.067 \\
\hline \%Men & 52.2 & 28.3 & 19.6 & & & -- \\
\hline \multicolumn{7}{|l|}{ Smoking habits } \\
\hline $\begin{array}{l}\text { \%Current } \\
\text { smokers }\end{array}$ & 36.8 & 31.6 & 31.6 & & & 0.665 \\
\hline \%Non-smokers & 30.7 & 34.1 & 35.2 & & & -- \\
\hline \multicolumn{7}{|l|}{ Physical activity } \\
\hline \%Low & 30.0 & 33.1 & 36.9 & & & 0.259 \\
\hline$\%$ Moderate & 42.9 & 32.1 & 25.0 & & & 0.483 \\
\hline \%High & 66.7 & 33.3 & -- & & & -- \\
\hline $\mathrm{WC}(\mathrm{cm}) * *$ & $112.62 \pm 1.67$ & $117.78 \pm 1.95$ & $119.95 \pm 1.49$ & & & 0.372 \\
\hline BMI $\left(\mathrm{kg} / \mathrm{m}^{2}\right)^{* *}$ & $27.69 \pm 0.95$ & $34.86 \pm 1.28$ & $37.86 \pm 0.81$ & $\begin{array}{c}\mathbf{0 . 1 6 3} \\
(0.028 \text { to } 0.298) \\
\end{array}$ & 1.17 & 0.018 \\
\hline SBP $(\mathrm{mmHg})$ & $138.24 \pm 3.86$ & $140.68 \pm 3.57$ & $145.53 \pm 3.06$ & & & 0.652 \\
\hline DBP (mmHg)* & $80.42 \pm 2.38$ & $82.84 \pm 1.84$ & $88.73 \pm 1.58$ & & & 0.117 \\
\hline FBG $(\mathrm{mg} / \mathrm{dL}) * *$ & $146.90 \pm 12.92$ & $177.13 \pm 13.99$ & $207.33 \pm 9.64$ & $\begin{array}{c}\mathbf{0 . 0 1 0} \\
(0.003 \text { to } 0.017) \\
\end{array}$ & 1.01 & 0.007 \\
\hline $\mathrm{TC}(\mathrm{mg} / \mathrm{dL}) * *$ & $194.10 \pm 4.95$ & $208.03 \pm 7.28$ & $209.69 \pm 5.37$ & & & 0.390 \\
\hline $\mathrm{TG}(\mathrm{mg} / \mathrm{dL}) * *$ & $166.76 \pm 18.08$ & $234.10 \pm 24.00$ & $235.69 \pm 13.76$ & & & 0.640 \\
\hline IL-6 $(\mathrm{pg} / \mathrm{mL})^{* *}$ & $1.60 \pm 0.10$ & $2.05 \pm 0.12$ & $2.39 \pm 0.11$ & $\begin{array}{c}\mathbf{0 . 8 0 2} \\
(0.102 \text { to } 1.502) \\
\end{array}$ & 2.22 & 0.025 \\
\hline $\begin{array}{l}\text { Adiponectin } \\
(\mathrm{mg} / \mathrm{L})^{* *}\end{array}$ & $13.20 \pm 0.98$ & $10.93 \pm 0.62$ & $8.55 \pm 0.53$ & $\begin{array}{c}\mathbf{- 0 . 2 0 4} \\
(-0.333 \text { to }- \\
0.076)\end{array}$ & 0.81 & 0.002 \\
\hline
\end{tabular}

\section{DISCUSSION}

This study identified the clinical risk factors associated with inflammation evidenced by high level of hsCRP in hypertensive diabetic patients. CRP is a sensitive marker of systemic inflammation that is synthesized by the liver [37]. The elevated levels of CRP has been linked directly with the development of major adverse effects of cardiovascular diseases in T2DM patients [30], endothelial dysfunction and atherosclerosis [38], metabolic syndrome and T2DM [39], as well as HT in normotensive adults [40].

As reported by Den Hertog et al. [41], the increased levels of CRP had been associated with increased mortality and morbidity rates in patients with ischemic heart disease and stroke, as it resulted in poor 
outcome and death. In the present study, the higher tertile of hs-CRP had been associated with higher anthropometric measurements of BMI and WC. It was also associated with poor biomedical data represented by high blood pressure, dysglycemia, dyslipidemia, and disturbances in adipokines.

The significant increment of biomedical data with higher tertile of hs-CRP is consistent with that found in previous studies. For instance, Santos et al. [42] found that CRP levels were significantly higher in high BP, hypertriglyceridemia, and hyperglycemia in a representative sample of urban adults to evaluate the association between CRP and metabolic syndrome. Likewise, Kawamoto et al. [43] found that CRP was higher significantly among the $\mathrm{FBG} \geq 100$ (mg/dL) group than the $\mathrm{FBG}<100(\mathrm{mg} / \mathrm{dL})$ group through a crosssectional study in Japan. In addition, Ajani et al. [44] found that the prevalence of high CRP increased for high lipid profile through an analysis of National Health and Nutrition Examination Survey 1999-2000.

Moreover, in order to identify the relationship of CRP with renal function loss in non-diabetic population, Stuveling et al. [45] found that the increased CRP had been associated with increased values of SBP, DBP, FBG, and TC. Similarly, Lee at al. [30] studied the role of inflammation with cardiovascular events, and discovered that CRP elevated significantly with the increase of DBP, FBG, TC, and TG, while the change of SBP did not reach the significance value with the change in CRP.

On the other hand, women in the present study had been associated with higher percentage of higher hs-CRP tertile, compared to men who achieved higher percentage of lower hs-CRP tertile. Consistently, in a metaanalysis conducted by Choi et al. [46], women had a stronger correlation of CRP than men in all ethnicity groups involving American, European, and Asian populations. Similarly, Thompson et al. [47] found that CRP was higher in women than men in China with high WC population, whereas Connelly et al. [48] agreed that the prevalence of high CRP $(\geq 3.8 \mathrm{mg} / \mathrm{L})$ among females was higher than the prevalence among male significantly in surveyed 512 community members aged 18 years and older in a study of Sandy Lake.

\section{Prediction of risk factors}

In the Ordinal Logistic Regression analysis, the obtained risk factors that had been associated with increased hs-CRP were the increased BMI, FBG, and IL-6, as well as decreased adiponectin. Indeed, the relationship of the total obesity evidenced by high BMI with inflammation has been well-described [49]. Besides, obesity has the potential to generate oxidative stress and inflammation in a healthy population [50,51], and both of them could mediate the development of metabolic syndrome due to obesity $[26,49]$.

Obesity is the main contributor to initiate the systemic inflammation in healthy adults though alteration on adipokine and/or inflammatory profiles are present [23]. Hansen et al. [52] compared the basal plasma adipokines and inflammatory markers between obese and non-obese T2DM by normoglycemic non-obese subjects and concluded that the observed alterations on adipokines and inflammatory markers in obese T2DM, as opposed to non-obese T2DM, had been attributed to the greater adipose tissue mass, and not necessarily due to the presence of diabetes.

Moreover, the overexpressed pro-inflammatory cytokines in obesity had been considered as the direct link between obesity and inflammation [51]. Adipose tissue responds to stimulation of extra nutrients via hyperplasia and hypertrophy of adipocytes [23]. The nature of adipose tissue is heterogeneous; including endothelium, immune cells, and adipocytes [53]. With progressive adipocyte enlargement and obesity, the blood supply to adipocytes is reduced and this leads to consequent hypoxia [54].

Hypoxia, on the other hand, has been proposed as an inciting etiology of necrosis and macrophage infiltration into adipose tissue, which leads to overproduction of pro-inflammatory mediators. This result in localized inflammation in adipose tissue that propagates an overall systemic inflammation associated with the development of obesity-related comorbidities [55]. Amongst the inflammatory mediators, three are produced by macrophages TNF- $\alpha$, IL-6, and adiponectin [56]. After that, the produced IL-6 in the adipose 
tissue of healthy humans is released into the circulation; inducing systemic inflammation, which is evaluated by the sensitive marker synthesized primarily by the liver CRP [57]. Moreover, the accumulation of free fatty acids in obesity activates pro-inflammatory serine kinase cascades, such as $\mathrm{I}_{\mathrm{k}} \mathrm{B}$ kinase and c-JunNterminal kinase, which in turn, promotes adipose tissue to release IL-6 that triggers hepatocytes to synthesize and secrete CRP [58].

Other than that, the antioxidant defense factors become lower due to obesity and accumulation of fat [59], and due to obesity, the level of adiponectin, which is totally anti-inflammatory, is exhausted by the state of inflammation [60,61]. In several reports, adiponectin has been considered as an important regulator of insulin sensitivity and glucose homeostasis by confirming an inverse relationship with insulin resistance [62]. This inverse association may possibly be mediated not only by insulin, but also by inflammation induced by adipokines like IL-6 [63].

In this study, the results revealed that the increased BMI was a risk factor and a predictor of elevated hsCRP. As shown in Figure 1 (Chart A), there is a direct correlation between BMI and hs-CRP $(r=0.345$, $\mathrm{P}<0.001$ ). As reported in previous studies, Lee et al. [30] found that the group with high tertile of hs-CRP was higher in BMI than other groups in a study intended to predict cardiovascular adverse effects in T2DM patients. Similarly, Pradhan et al. [64] evaluated the level of inflammatory markers among diabetic and healthy US women through a prospective case-control study to display the role of inflammatory markers CRP and IL-6. The level of CRP had a direct escalation by increasing the level of BMI for both case and control women. The mean of BMI for case group was $\left(31.8 \mathrm{~kg} / \mathrm{m}^{2}\right)$ and for control group was $\left(25.6 \mathrm{~kg} / \mathrm{m}^{2}\right)$; the median of CRP for case group was $(0.69 \mathrm{mg} / \mathrm{dL})$, which had been significantly higher than control group $(0.26 \mathrm{mg} / \mathrm{dL})$. Moreover, Escobar-Morreale et al. [65] concluded that obesity is the main determinant to elevate inflammatory markers CRP and IL-6 compared with lean bodies among pre-menopause women. In addition, Visser et al. [66] reported that the CRP level was higher among obese than non-obese in a study that included males and non-pregnant females aged 17 years and older.

Furthermore, the results showed that the increased level of IL-6 was well-associated with elevated hs-CRP. As shown in Figure 1 (Chart B), IL-6 directly correlated with hs-CRP $(r=0.558, \mathrm{P}<0.001)$. This result is strongly agreed by Indulekha et al. [67] who found that CRP increased in individuals who had elevated level of IL-6 among Asian Indians after distributing the population into four groups (diseased obese, healthy obese, diseased-non obese, and healthy non-obese). Similarly, Wannamethee et al. [68] found a strong and significant association between IL-6 and CRP $(\mathrm{P}<0.001)$ during the evaluation of risk factors associated with metabolic syndrome and CVDs among overaged British in several towns. In the same vein, Tsilchorozidou et al. [69] found strong correlation between IL-6 and CRP $(r=0.59)$ in women with polycystic ovary syndrome. In addition, Ridker et al. [70] studied the association between IL- 6 and CRP in 202 myocardial infarction patients and 202 apparently healthy participants matched by age and sex; where significant correlation was indicated $(r=0.43, \mathrm{P}<0.001)$. In fact, the results of the current study and past literatures have approved the strong association and effect of IL-6 on the elevation of hs-CRP.

Moreover, the results represented that the decreased levels of adiponectin were well-associated with elevated hs-CRP. As shown in Figure 1 (Chart C), adiponectin inversely correlated with hs-CRP $(r=-0.331$, $\mathrm{P}=0.001)$. This result is consistent with that obtained by Sedighi and Abediankenari [71], in a study on chronic kidney disease patients, where they found inverse correlation between adiponectin and CRP ( $r=$ 0.548, $\mathrm{P}<0.001$ ). Likewise, Hung et al. [72] found that the levels of CRP and IL-6 could predict negative values of adiponectin after adjustments were to age, sex, and waist to hip ratio; where the estimated regression coefficient was $[-4.56], \mathrm{P}<0.001$, and $[-3.46], \mathrm{P}=0.001$, respectively, while the estimation of regression was still significant after adding smoking habits.

Finally, this study proved the effect of diabetes, evidenced by high level of FBG on inflammation featured by hs-CRP. This effect has further asserted the positive correlation between FBG and hs-CRP $(r=0.246$, $\mathrm{P}=0.001$ ), as shown in Figure 1 (Chart D). Similar results were also observed in previous studies. Kawamoto 
et al. [43] found CRP higher significantly $(\mathrm{P}=0.033)$ among the $\mathrm{FBG} \geq 100(\mathrm{mg} / \mathrm{dL})$ group than the $\mathrm{FBG}<100$ $(\mathrm{mg} / \mathrm{dL})$ group through a cross-sectional study carried out in Japan. Likewise, Santos et al. [42] found that the CRP levels were significantly higher among urban adults with high FBG compared to low level (1.96 vs. $1.46, \mathrm{P}=0.032$ ) in order to evaluate the association between $\mathrm{CRP}$ and metabolic syndrome.

[Figure 1 Bivariate correlations, Chart A: BMI with hs-CRP, Chart B: IL-6 with hs-CRP, Chart C: adiponectin with hs-CRP, Chart D: FBG with hs-CRP]

\section{CONCLUSION}

The presence of inflammation featured by hs-CRP could predict metabolic dysregulation in hypertensive patients with T2DM. The group of patients with higher tertile of hs-CRP displayed major metabolic abnormalities, including dysglycaemia, dyslipidemia, higher BP, and metabolic obesity indexed by adipokines activity. Besides, the results of the investigation retrieved from this study proved the role of obesity in promoting systemic inflammation. BMI was a risk factor of elevated hs-CRP, while the conjugated risk factors of increased IL-6 and reduced adiponectin were strongly linked to obesity [23,56]. In fact, similarity in these results was observed in Al-Hamodi et al. [27] study that proved the role of obesity on adiponectin and inflammation. In addition to obesity, this study proved the role of diabetes evidenced by hyperglycemia in initiating inflammation that could lead to major adverse effects. Therefore, controlling diabetes and managing weight through positive lifestyle patterns can reduce the incidence of chronic inflammation and further complications.

\section{ACKNOWLEDGEMENT}

The authors would like to extend their sincere gratitude to the participants for their willingness to participate in this study, and to the Palestinian Ministry of Health for granting the permission to conduct the fieldwork. In addition, the author would also like to thank the Faculty of Medicine and Health Sciences at Universiti Putra Malaysia for the use of its library.

\section{CONFLICT OF INTEREST}

The author declare that there is no significant competing financial, professional or personal interests that may influence the performance or the presentation of the work described in this manuscript.

\section{REFERENCES}

1. Mackay J, Mensah G (2004). Atlas of heart disease and stroke. Geneva: World Health Organization.

2. Krause T, Lovibond K, Caulfield M, McCormack T, Williams B (2011). Management of hypertension: summary of NICE guidance. BMJ 343:d4891 doi: 10.1136/bmj.d4891

3. Lim SS, Vos T, Flaxman AD, Danaei G, Shibuya K, Adair-Rohani H, et al. (2012). A comparative risk assessment of burden of disease and injury attributable to 67 risk factors and risk factor clusters in 21 regions, 1990-2010: a systematic analysis for the Global Burden of Disease Study 2010. Lancet 380: 2224-2260.

4. Ogah OS, Okpechi I, Chukwuonye II, Akinyemi JO, Onwubere BJ, Falase AO, et al. (2012). Blood pressure, prevalence of hypertension and hypertension related complications in Nigerian Africans: A review. World Journal of Cardiology 4(12): 327-340. 
5. Mitu F, Rezuş E, Banu C, Jufã C, Mitu O, Dima-Cozma C (2014). Inflammatory markers in hypertensive patients and influence of some associated metabolic risk factor. Revista medico-chirurgicala a Societatii de Medici si Naturalisti din Iasi 118(3): 631-6.

6. Ellulu MS, Rahmat A, Abed Y, Baloushah S, Patimah I, Khazaai H. Assessment of differences on inflammatory and metabolic indicators between pre- and post-menopause women among hypertensive and/or diabetic patients. Trends in Medical Research. 2015; 10(2):44-50. doi: 10.3923/tmr.2015.44.50.

7. Mühlenbruch K, Joost HG, Boeing H, Schulze MB (2014). Risk prediction for type 2 diabetes in the German population with the updated German Diabetes Risk Score (GDRS). Ernährungsumschau 61: 9093.

8. Centers for Disease Control and Prevention (CDC) (2011). National diabetes fact sheet: national estimates and general information on diabetes and prediabetes in the United States, 2011. Atlanta, GA: US Department of Health and Human Services, Centers for Disease Control and Prevention, 2011.

9. American Diabetes Association (2015). 2. Classification and Diagnosis of Diabetes. Diabetes Care 38(Supplement 1): S8-S16.

10. Ceriello PA (2006). Oxidative stress and diabetes associated complications. Endocrine Practice 12:6062.

11. Bruno, R. M., Penno, G., Daniele, G., Pucci, L., Lucchesi, D., Stea, F., ... \& Del Prato, S. (2012). Type 2 diabetes mellitus worsens arterial stiffness in hypertensive patients through endothelial dysfunction. Diabetologia, 55(6), 1847-1855.

12. Gordon, L., Ragoobirsingh, D., Morrison, E., McGrowder, D., Choo-Kang, E., \& Martorell, E. (2010). Dyslipidaemia in hypertensive obese type 2 diabetic patients in Jamaica. Arch Med Sci 6(5): 701-708.

13. Maschirow, L., Khalaf, K., Al-Aubaidy, H. A., \& Jelinek, H. F. (2015). Inflammation, coagulation, endothelial dysfunction and oxidative stress in prediabetes-Biomarkers as a possible tool for early disease detection for rural screening. Clinical Biochemistry. 48: 581-585

14. Kalyani RR, Saudek CD, Brancati FL, Selvin E (2010) Association of diabetes, comorbidities, and A1C with functional disability in older adults results from the National Health and Nutrition Examination Survey (NHANES), 1999-2006. Diabetes Care 33:1055-1060.

15. Weng X, Liu Y, Ma J, Wang W, Yang G, Caballero B (2006). Use of body mass index to identify obesity-related metabolic disorders in the Chinese population. European Journal of Clinical Nutrition 60(8): 931-937.

16. World Health Organization (2015). Overweight and Obesity. Fact Sheet No. 311. Updated January 2015. http://www.who.int/mediacentre/factsheets/fs311/en/

17. Tee SR, Teoh X, Aiman W, Aiful A, Har C, Tan Z, et al. (2010). The prevalence of hypertension and its associated risk factors in two rural communities in Penang, Malaysia. IeJSME 2:27-40.

18. Weber MA, Schiffrin E, White WB, Mann S, Lindholm LH, Kenerson JG, et al. (2014). Clinical practice guidelines for the management of hypertension in the community. The Journal of Clinical Hypertension 16(1): 14-26.

19. Kim SY, Lee SJ, Park H, Yun J, Lee M, Sung J, et al. (2011). Adiponectin is Associated with Impaired Fasting Glucose in the Non-Diabetic Population. Epidemiology and Health 33: e2011007.

20. Jensen MD: Role of body fat distribution and the metabolic complications of obesity. J Clin Endocrinol Metab 2008, 93:S57-S63.

21. Rasouli N, Kern PA: Adipocytokines and the metabolic complications of obesity. J Clin Endocrinol Metab 2008, 93:S64-S73

22. Mirza S, Hossain M, Mathews C, Martinez P, Pino P, Gay JL, Rentfro A, McCormick JB, Fisher-Hoch SP: Type 2-diabetes is associated with elevated levels of TNF-alpha, IL-6 and adiponectin and low levels of leptin in a population of Mexican Americans: a cross-sectional study. Cytokine 2012, 57(1):136-1

23. Emanuela F, Grazia M, Marco DR, Paola LM, Giorgio F, Marco B (2012). Inflammation as a Link between Obesity and Metabolic Syndrome: Review Article. Journal of Nutrition and Metabolism. DOI: $10.1155 / 2012 / 476380$.

24. Ricci R, Bevilacqua F (2012). The potential role of leptin and adiponectin in obesity: A comparative review. The Veterinary Journal 191: 292-298 
25. Herder C, Schneitler S, Rathmann W, Haastert B, Schneitler H, Winkler H, Bredahl R, Hahnloser E, Martin S: Low-grade inflammation, obesity, and insulin resistance in adolescents. J Clin Endocrinol Metab 2007, 92:4569-4574.

26. Ellulu, M. S., Patimah, I., Khaza'ai, H., Rahmat, A., \& Abed, Y. (2017). Obesity and inflammation: the linking mechanism and the complications. Archives of Medical Science: AMS, 13(4), 851.

27. Al-Hamodi, Z., Al-Habori, M., Al-Meeri, A., \& Saif-Ali, R. (2014). Association of adipokines, leptin/adiponectin ratio and C-reactive protein with obesity and type 2 diabetes mellitus. Diabetol Metab Syndr, 6(1), 99.

28. Cirillo P, Sautin Y, Kanellis J, Kang D, Gesualdo L, Nakagawa T, et al. (2009). Systemic inflammation, metabolic syndrome and progressive renal disease. Nephrology Dialysis Transplantation 24(5):13841387.

29. Woodard G, Mehta V, Mackey R, Tepper P, Kelsey S, Newman A, et al. (2011). C-reactive protein is associated with aortic stiffness in a cohort of African American and white women transitioning through menopause. Menopause 18(12): 1291-1297.

30. Lee S, Kim IT, Park HB, Hyun YK, Kim YJ, Song SO, et al. (2011). High-sensitivity C-reactive Protein Can Predict Major Adverse Cardiovascular Events in Korean Patients with Type 2 Diabetes. Journal of Korean Medical Science 26: 1322-1327

31. Ridker PM (2003). C-Reactive Protein: A Simple Test to Help Predict Risk of Heart Attack and Stroke. Circulation 108:e81-e85.

32. Bahceci M, Gokalp D, Bahceci S, Tuzcu A, Atmaca S, Arikan S: The correlation between adiposity and adiponectin, tumor necrosis factor alpha, interleukin-6 and high-sensitivity c-reactive protein levels. Is adipocyte size associated with inflammation in adults? J Endocrinol Invest 2007, 30(3):210-214.

33. Centers for Disease Control and Prevention (2011). Behavioral risk factor surveillance system survey questionnaire. Atlanta, Georgia: US Department of Health and Human Services, Centers for Disease Control and Prevention.

34. World Health Organization (WHO) Department of Non-communicable Diseases. Global Physical Activity Questionnaire: Analysis Guide. Geneva: WHO; 2002. Available from: http://www.who.int/chp/steps/resources/GPAQ_Analysis_Guide.pdf. Accessed May 26, 2015.

35. World Health Organization (WHO). Obesity: Preventing and Managing the Global Epidemic: Report of a WHO Consultation. WHO Technical Report Series 894. Geneva: WHO; 2000. Available from: http://www.who.int/nutrition/publications/obesity/WHO_TRS_894/en/. Accessed May 26, 2015

36. National Institute for Health and Clinical Excellence. Obesity: The Prevention, Identifiation, Assessment and Management of Overweight and Obesity in Adults and Children. London: National Institute for Health and Clinical Excellence; 2006.

37. Backes JM, Howard PA, Moriarty P (2004). Role of C-reactive protein in cardiovascular disease. The Annals of Pharmacotherapy 38: 110-118.

38. Devaraj S, Yun J, Adamson G, Galvez J, Jialal I (2009). C-reactive protein impairs the endothelial glycocalyx resulting in endothelial dysfunction. Cardiovascular Research 84: 479-484.

39. Han TS, Sattar N, Williams K, Gonzalez-Villalpando C, Lean M, Haffner S (2002). Prospective Study of C-Reactive Protein in Relation to the Development of Diabetes and Metabolic Syndrome in the Mexico City Diabetes Study. Diabetes Care 25:2016-2021

40. Sesso HD, Buring JE, Rifai N, Blake GJ, Gaziano JM, Ridker PM (2003). C-Reactive Protein and the Risk of Developing Hypertension. JAMA 290(22): 2945-2951.

41. Den Hertog HM, van Rossum JA, van der Worp HB, van Gemert HMA, de Jonge R, Koudstaal PJ, et al. (2009). C-reactive protein in the very early phase of acute ischemic stroke: association with poor outcome and death. Journal of Neurology 256:2003-2008.

42. Santos AC, Lopes C, Guimarães JT, Barros H (2005). Central obesity as a major determinant of increased high-sensitivity $\mathrm{C}$-reactive protein in metabolic syndrome. International Journal of Obesity (Lond) 29(12):1452-6. 
43. Kawamoto R, Tabara Y, Kohara K, Miki T, Kusunoki T, Takayama S, et al. (2011). Association between fasting plasma glucose and high-sensitivity C-reactive protein: gender differences in a Japanese community-dwelling population. Cardiovascular Diabetology 10:51. doi:10.1186/1475-2840-10-51.

44. Ajani UA, Ford E, Mokdad A (2004). Prevalence of High C-Reactive Protein in Persons with Serum Lipid Concentrations within Recommended Values. Clinical Chemistry 50(9): 1618-1622.

45. Stuveling EM, Hillege HL, Bakker S, Gans R, de Jong PE and de Zeeuw D (2003). C-reactive protein is associated with renal function abnormalities in a non-diabetic population. Kidney International 63:654661.

46. Choi J, Joseph L, Pilote L (2013). Obesity and C-reactive protein in various populations: a systematic review and meta-analysis. Obesity Reviews 14: 232-244.

47. Thompson A, Houck K, Adair L, Gordon-Larsen P, Popkin B (2014). Risk factors for moderate inflammation in Chinese adults with and without central obesity (370.1). The FASEB Journal 28(1 Supplement): 370 .

48. Connelly PW, Hanley AJ, Harris SB, Hegele RA, Zinman B (2003). Relation of waist circumference and glycemic status to C-reactive protein in the Sandy Lake Oji-Cree. International Journal of Obesity 27:347-354. doi:10.1038/sj.ijo.0802239

49. Scheller J, Chalaris A, Schmidt-Arras D, Rose-John S (2011). The pro- and anti inflammatory properties of the cytokine interleukin-6. Biochimica et Biophysica Acta (BBA)-Molecular Cell Research 1813(5): 878-888.

50. Chen SJ, Yen CH, Huang YC, Lee BJ, Hsia S, Lin PT (2012). Relationships between Inflammation, Adiponectin, and Oxidative Stress in Metabolic Syndrome. PLoS ONE 7(9): e45693. doi:10.1371/journal.pone.0045693.

51. Hotamisligil GS (2006). Inflammation and metabolic disorders. Nature 444 (7121): 860-867.

52. Hansen D, Dendale P, Beelen M, Jonkers RAM, Mullens A, Corluy L, Meeusen R, van Loon LJC: Plasma adipokine and inflammatory marker concentrations are altered in obese, as opposed to nonobese, type 2 diabetes patients. Eur J Appl Physiol 2010, 109:397-404

53. Halberg N, Wernstedt-Asterholm I, Scherer PE (2008). The adipocyte as an endocrine cell. Endocrinology and Metabolism Clinics of North America 37(3): 753-768.

54. Cinti S, Mitchell G, Barbatelli G, Murano I, Ceresi E, Faloia E, et al. (2005). Adipocyte death defines macrophage localization and function in adipose tissue of obese mice and humans. Journal of Lipid Research 46(11): 2347-2355.

55. Trayhurn P, Wood I (2004). Adipokines: inflammation and the pleiotropic role of white adipose tissue. British Journal of Nutrition 92(3): 347-355.

56. Karastergiou K, Mohamed-Ali V (2010). The autocrine and paracrine roles of adipokines. Molecular and Cellular Endocrinology 318(1-2): 69-78.

57. Zhang S, Liu Q, Wang J, Harnish DC (2009). Suppression of interleukin-6-induced Creactive protein expression by FXR agonists. Biochemical and Biophysical Research Communications 379(2): 476-479.

58. Rocha VZ, Libby P (2009). Obesity, inflammation, and atherosclerosis. Nature Reviews Cardiology 6(6): 399-409.

59. Chrysohoou C, Panagiotakos DB, Pitsavos C, Skoumas I, Papademetriou L, Economou M, et al. (2007). The implication of obesity on total antioxidant capacity in apparently healthy men and women: the ATTICA study. Nutrition, Metabolism and Cardiovascular Diseases 17(8): 590-597.

60. Delgado-Lista J, Perez-Martinez P, Lopez-Miranda J, Perez-Jimenez F (2012). Long chain Omega-3 fatty acids and cardiovascular disease: a systematic review. British Journal of Nutrition 107: S201-S213.

61. Badawi A, Klip A, Haddad P, Cole D, Bailo B, El-Sohemy A, et al. (2010). Type 2 diabetes mellitus and inflammation: Prospects for biomarkers of risk and nutritional intervention. Diabetes, Metabolic Syndrome \& Obesity: Targets \& Therapy 3: 173-186.

62. Ohashi K, Ouchi N, Matsuzawa Y: Anti-inflammatory and anti-atherogenic properties of adiponectin. Biochimie 2012, 94:2137-2142 
63. Fasshauer M, Kralisch S, Klier M, Lossner U, Bluher M, Klein J, Paschke R: Adiponectin gene expression and secretion is inhibited by interleukin-6 in 3 T3-L1 adipocytes. Biochem Biophys Res Commun 2003, 301:1045-1050.

64. Pradhan A, Manson J, Rifai N, Buring J, Ridker P (2001). C-Reactive Protein, Interleukin 6, and Risk of Developing Type 2 Diabetes Mellitus. JAMA 682: 327-334.

65. Escobar-Morreale H, Villuendas G, Botella-Carretero J, Sancho J, San Millán J (2003). Obesity, and not insulin resistance, is the major determinant of serum inflammatory cardiovascular risk markers in premenopause women. Diabetologia 46: 625-633.

66. Visser M, Bouter L, McQuillan G, Wener M, Harris T (1999). Elevated C-reactive protein levels in overweight and obese adults. JAMA 282(22): 2131-2135.

67. Indulekha K, Surendar J, Anjana R, Geetha L, Gokulakrishnan K, Pradeepa R, et al. (2015). Metabolic Obesity, Adipocytokines, and Inflammatory Markers in Asian Indians-CURES-124. Diabetes Technology \& Therapeutics 17(2):134-41.

68. Wannamethee SG, Whincup PH, Rumley A, Lowe G (2007). Inter-relationships of interleukin-6, cardiovascular risk factors and the metabolic syndrome among older men. Journal of Thrombosis and Haemostasis 5(8): 1637-1643.

69. Tsilchorozidou T, Mohamed-Ali V, Conway GS (2009). Determinants of interleukin-6 and C-reactive protein vary in polycystic ovary syndrome, as do effects of short- and long-term metformin therapy. Hormones Research 71(3):148-54.

70. Ridker PM, Rifai N, Meir J. Stampfer MJ, Hennekens CH (2000). Plasma concentration of interleukin-6 and the risk of future myocardial infarction among apparently healthy men. Circulation 101: 1767-1772.

71. Sedighi O, Abediankenari S (2013). Relationship between plasma adiponectin level with inflammatory and metabolic markers in patients with chronic kidney disease. Nephrourology Monthly 6(1):e11743. doi: 10.5812/numonthly.11743. eCollection 2014.

72. Hung J, McQuillan BM, Thompson PL, Beilby JP (2008). Circulating adiponectin levels associate with inflammatory markers, insulin resistance and metabolic syndrome independent of obesity. International Journal of Obesity 32: 772-779. 

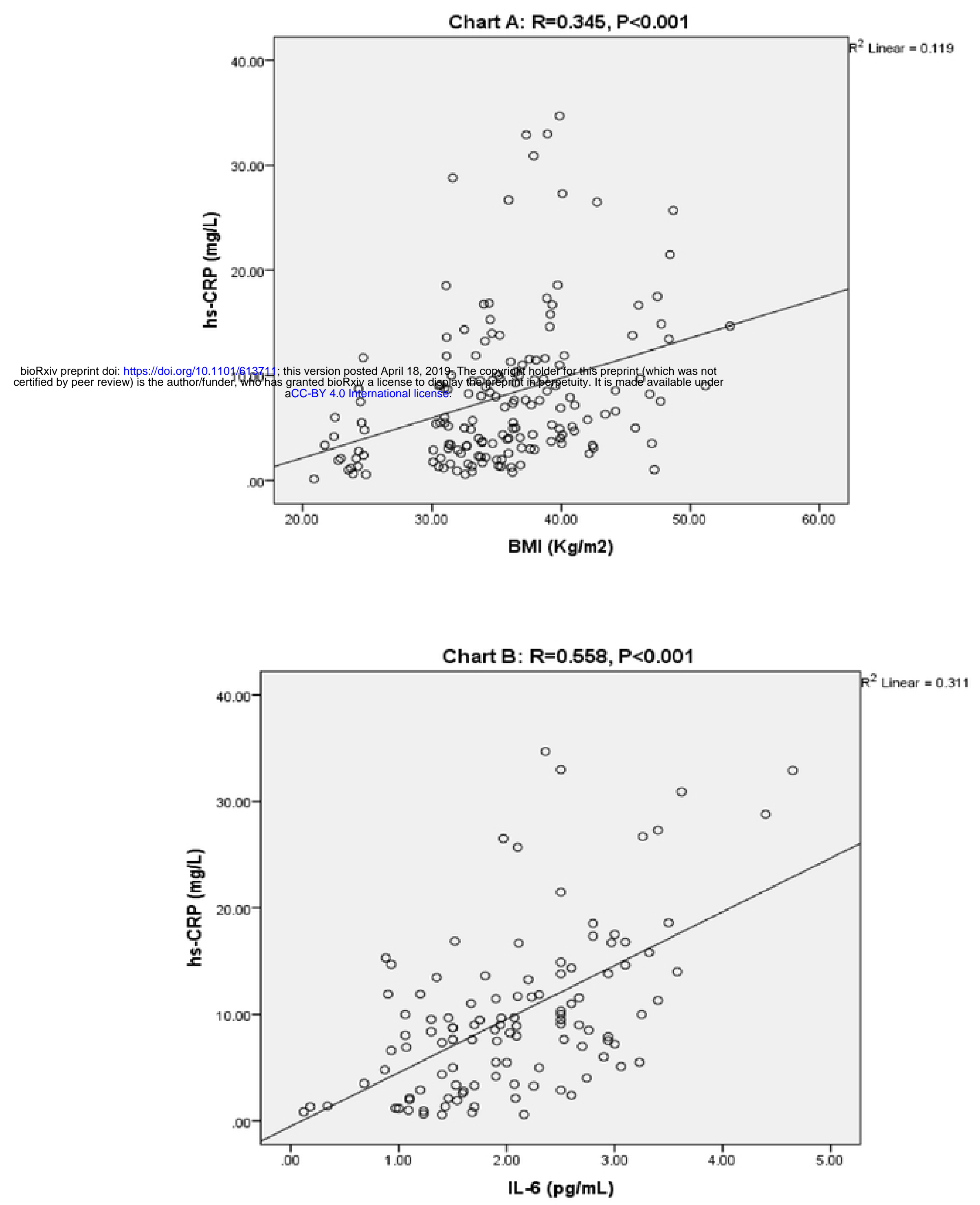

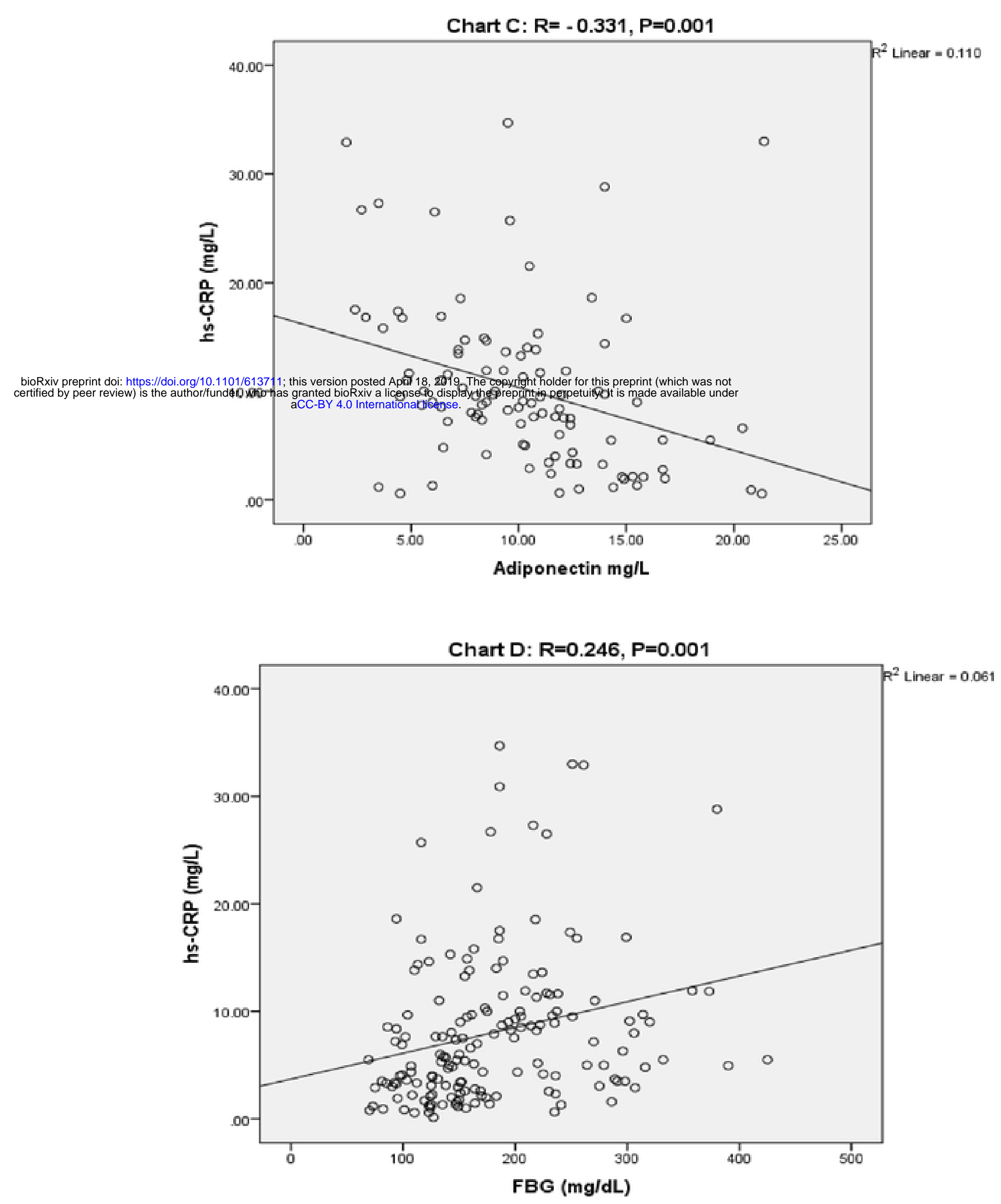

[Figure 1 Bivariate correlations, Chart A: BMI with hs-CRP, Chart B: IL-6 with hs-CRP, Chart C: adiponectin with hs-CRP, Chart D: FBG with hs-CRP] 